\title{
Teologia, Ética e Sociedade: reflexões sobre o bem-viver a partir da antropologia filosófica de Paul Ricoeur
}

\author{
Theology, Ethics and Society: reflections on the well-living from \\ the philosophical-theological anthropology of Paul Ricoeur
}

\section{José Aguiar Nobre*}

Universidade Federal do Paraná (UFPR), Curitiba, PR, Brasil

\section{Resumo}

A contemporaneidade é uma época propícia para se discutir a distinção entre o justo e o bom. Entende-se que essa distinção está diretamente vinculada às relações intrínsecas do Estado secular, muitas vezes indiferente ao cuidado com a justiça social, cujas consequências ceifam vidas, ora de forma velada, ora desveladamente, contrariando assim a teologia da criação. Esta é inteiramente soteriológica e não poderá jamais se contentar com o estado de deterioração humana. É da natureza das sociedades democráticas relacionar várias concepções atreladas à ética do bem viver, circunscritas ao bom e ao bem, dentro de uma mesma sociedade. Essa relação muitas vezes em intersecção invisível está ligada à necessidade cristã de reivindicar uma situação justa para todos. Defende-se que cada um deverá perseguir o seu próprio bem, o seu próprio sentido de bem, cultivando o entendimento de que a condição para isso é o bem da coletividade. Naturalmente, as comunidades diferentes têm concepções divergentes

*JAN: Doutor em Teologia Sistemático-Pastoral, e-mail: nobre.jose@gmail.com 
de bem e de bom, no entanto, precisam conviver numa mesma sociedade e aí reside a problemática: como atingir o bem-viver garantindo a justiça para todos? Indaga-se: o que é afinal o "bem-viver", segundo o pensamento de Paul Ricoeur? Atrelada à esta indagação vem a pergunta pelos seus caminhos, a saber: quais os caminhos para a genuína efetivação do bem-viver? Hipoteticamente entende-se que o bem viver se atinge quando o ser humano está bem consigo mesmo, com os outros e atuando, civilizadamente, nas instituições justas em prol da vida digna em comunidade.

Palavras-chave: Bem-viver. Ética. Sociedade. Justiça. Paul Ricoeur.

\section{Abstract}

Contemporaneity is a propitious time to discuss the distinction between the just and the good. It is understood that this distinction is directly linked to the intrinsic relations of the secular state, often indifferent to caring for social justice, the consequences of which take lives, sometimes in a veiled way, sometimes unveiled, thus contradicting the theology of creation. This is entirely soteriological and can never be satisfied with the state of human decay. It is in the nature of democratic societies to relate various conceptions linked to the ethics of well-being, circumscribed to good and good, within a single society. This relationship, often at an invisible intersection, is linked to the Christian need to claim a just situation for all. It is argued that each should pursue his own good, his own sense of good, cultivating the understanding that the condition for this is the good of the collectivity. Naturally, different communities have different conceptions of good and good, but they must live together in the same society, and therein lies the problem: how to achieve well-being by guaranteeing justice for all? We ask ourselves: what, in the words of Paul Ricoeur, is "well-being" after all? Linked to this question comes the question of their ways, namely: what are the paths to the genuine realization of well-being? It is hypothetically understood that good living is achieved when the human being is well with himself, with others and acting, civilly, in the just institutions for the dignified life in community.

Keywords: Well-living. Ethic. Society. Justice. Paul Ricoeur. 


\section{Introdução}

Em face das grandes e preocupantes questões éticas e políticas latentes na sociedade hodierna, o presente trabalho procurará trazer uma contribuição fundamentada no tema do bem-viver circunscrito na perspectiva da ética ricoeuriana e em interlocução com o desafio cristão de busca da realização humana. Como se sabe, a antropologia filosófica do pensador francês, Paul Ricouer, fundamenta-se na articulação entre as tradições aristotélicas e kantianas, apontando diretamente para a questão da justiça equitativa e do dever ser. Na presente pesquisa, explorar-se-á os sentidos da "estima de si" e do "respeito de si", entendendo que esses sentidos conduzirão o ser humano a interpretar-se a si próprio como autor de suas ações, provocando-o à sua própria auto avaliação. Entende-se que ao levar em conta os seres humanos como "sujeitos do desejo", as reflexões acerca da vida boa, a partir do pensamento de Paul Ricoeur, em plena intersecção ético-política frente à sua postura social, levantarão questões antropológicas com um viés de alteridade. Questões que, uma vez visualizadas, serão exploradas ao longo da existência humanas, na medida em que o ser humano se torna educado para o coletivo. A literatura de Paul Ricoeur, tece ponderações acerca das relações humanas e da qualidade dessas relações, teorizando sobre as possibilidades ou não de realização dos desejos e consequente busca do viver plenamente. Numa palavra, no conjunto das ponderações do ser humano educado para o coletivo, tudo converge para um olhar sobre as consequências individuais, institucionais e sociais das ações humanas.

Argumenta-se que o bem viver, do ponto de vista da filosofia de Paul Ricoeur caracteriza-se essencialmente pela relação do ser humano com os seus pares, isto é não se pensa em alcançar a vida plena de modo solitário. Essa caracterização tem a estima de si como um ponto fundamental para reconhecer o próprio dever de praticar ações boas e afirmá-las sempre. O campo de realização do bem viver ricoeuriano materializa-se no âmbito da hierarquização da práxis. Esta, objetiva levar o sujeito a compreender que ele vive inserido na sociedade pela qual é julgado. A perspectiva do bem viver cuja intersecção cristã e ético-moral, reivindica a compreensão de que a ética circunscreve a moral e ambas se complementam, de modo 
que uma não se desenvolve desvinculada da outra. No que diz respeito à moral, reiterar-se-á que a reflexão filosófico-tológica de Ricoeur está atrelada à reflexão aristotélica bem como à fonte kantiana que teorizam sobre a norma com pretensão de universalidade. Neste campo está circunscrito também o respeito de si como correspondência ao momento deontológico ou do dever ser. Entender-se-á que Paul Ricoeur fundamenta-se no formalismo e na universalidade kantianas para conjugar a vida boa com a obrigação moral. Atrelada a essa tarefa, está a questão do si que pergunta pelo caráter ético do sujeito da ação, o qual será responsabilizado por seus atos. Esta reflexão aponta para a questão da identidade e da ipseidade, que enfatizam o sujeito da ação. Estas reflexões desembocam na esfera ética do si e na sua dimensão triádica: a estima de si, a solicitude para com os outros e a justiça em relação a cada um. Entende-se assim que este tripé está diretamente atrelado à ação responsável do sujeito nas relações consigo mesmo e com o outro nas instituições justas. A partir deste preâmbulo, entender-se á então, de forma mais ampla, os componentes éticos, teológicos e sóciológico de Paul Ricoeur.

\section{0 que é o "bem-viver"?}

A primeira tarefa que se põe nesta indagação é a busca pelo seu conceito. O que se entende pela expressão "bem-viver" na perspectiva da ética de Paul Ricoeur? Ao que se compreende imediatamente como "vida boa", "vida feliz", "vida concluída", isto é, uma "vida realizada" que, a partir da perspectiva teológica se chama de vida plena. Sendo assim, o bem-viver, segundo Paul Ricoeur, se desenvolve ou é possível numa perspectiva social e comunitária. Em outras palavras, é uma questão circunscrita à educação para a constituição genuína do sujeito coletivo, do ser humano que saiba viver de modo civilizado em sociedade, em detrimento de um ser isolado e egoísta.

O bem viver se mostra como um fio condutor da perspectiva ética de Paul Ricoeur, a saber: "Chamamos 'perspectiva ética', a perspectiva da 'vida boa' com e para outros nas instituições justas” (RICOEUR, 1999, p. 202). A vida boa entendida por Ricoeur não é, então, uma vida isolada, 
anti-social, mas é, antes de tudo, uma vida que se vive em sociedade, respeitando e valorizando a si-mesmo, o diverso de si e das instituições. Uma vida que procura ver sempre, e em primeiro lugar, a pessoa humana nas suas mais variadas culturas, sem jamais subjugá-la, de modo primordial dispensando os empobrecidos pois que são frutos de injustiças e em contraposição com o ideal do Evangelho. E, desse modo tem na regra de ouro, a sua inspiração. Esta regra está relatada em Mt 7,12): “Tudo o que vocês desejam que os outros façam a vocês, façam vocês também a eles”. É um viver livre da prática de preconceitos, marcado pela reciprocidade, admiração e atenção para consigo e para como os outros. O que leva o ser humano a uma auto interpretação de si e das diferentes culturas, a uma auto avaliação em busca da aproximação à verdade do Evangelho. Desenvolvese, desse modo, sempre num espírito da busca de uma coexistência pacífica, pois, da obra de Paul Ricoeur depreende-se que a pessoa só vive bem, no mundo globalizado da atualidade, quando é capaz de con-viver consigo mesma e com o outro, nas suas relações de vida cotidiana: empresas e sociedade em geral. Outro texto evangélico que remete a esse mesmo espírito teológico missionário é Jo 13,35: "Se vocês tiverem amor uns para com os outros, todos reconhecerão que sois meus discípulos".

A vida boa na perspectiva da ética teológica de Paul Ricoeur não pretende se fechar em si, mas viver a alteridade; nem também viver uma vida devassa, mas uma vida regrada com um objetivo expansivo, aberto de crescimento humano em busca de saídas práticas no relacionamento da ipseidade ${ }^{1}$, que se dá nas situações singulares conhecida como sabedoria prática ou prudência; por isso, é um campo estritamente ético. A esse respeito, confira o que diz o autor: "O aparecimento da palavra "vida" merece reflexão. Ela não é tomada num sentido puramente biológico, mas no sentido ético-cultural, [...], designa o homem completo por oposição às práticas fragmentárias" (RICOEUR, 1999, p. 209). Para Paul Ricoeur, o termo vida designa ao mesmo tempo um enraizamento biológico da vida e a unidade do ser humano por completo, enquanto é esse ser humano que lança sobre si mesmo o olhar da apreciação de sua própria vida, pois deve ter a consciência de que é alguém que age e que sofre ações exteriores.

1 Significa a identidade pessoal e reflexiva, talhada pela alteridade. 
Trata-se de um processo ético no qual o ser humano vai reconhecendo-se claramente que sua grande tarefa é qualificar-se sempre como ser humano realizado. Esse qualificar-se como ser humano que tem uma origem divina, reivindica o reconhecimento recíproco do valor existente no outro, cujo Mistério ali também faz morada.

Reportando à dialética do senhor e do escravo, é possível entender então que é mediante o "reconhecimento mútuo e recíproco, o único que pode realizar e satisfazer plena e definitivamente o homem" (KOJÈVE, 2002, p. 25). Fora desse viés de reciprocidade, o ser humano será sempre um eterno insatisfeito e escravo dos seus caprichos. A obra de Paul Ricoeur aponta, portanto, que, ao mesmo tempo em que é levada em conta a presença significativa do semelhante, é o próprio ser humano em processo de crescimento o responsável primeiro por essa sua qualificação enquanto ser responsável por si mesmo. Da mesma forma que em qualquer perspectiva antropocentrista o reconhecimento vem especificamente por parte do outro. Paradoxalmente, o escravo que é referido por Alexandre Kojève, ao observar o seu senhor no processo de "negatividade-negadora", lhe confere reconhecimento ao arriscar a sua vida na luta por esse reconhecimento. Na perspectiva ética do bem viver ricoeuriano, há um passo além, isto é, o próprio ser humano é capaz de se auto-interpretar, de trabalhar segundo uma intenção, buscando o sentido das coisas a fim de detectar os erros para eliminá-los. Isso constitui num desejo de crescimento, rumo a uma vida adulta crítico-reflexiva. Assim, no reconhecimento do plano de vida boa, o ser humano educado para a vida coloca-se no mundo da apreciação de si e do diverso de si. Tem um ideal de bem-viver sempre equilibrado entre as objetivações da vida e o refletir sobre elas. Do ponto de vista de uma fluída e refinada reflexão do agir humano, observe as palavras do filósofo francês sobre o que é o bem viver:

Com referência ao conteúdo, "vida boa" é, para cada um, a nebulosa de ideais e de sonhos de cumprimento com respeito à qual uma vida é considerada mais ou menos realizada ou irrealizada. É o "em vista de que" tendem essas ações das quais dissemos, todavia, que tinham seu fim em si mesmas. [...] O que se pensa aqui é a ideia de uma filosofia superior que não deixaria de ser interior ao agir humano (RICOEUR, 1999, p. 210). 
Para Ricoeur, mais do que agir tendo em vista o olhar de outrem, o bem viver é um trabalho incessante de auto-interpretação das ações humanas, a fim de melhor adequar a sua vida aos ideais que se aspira, governando e direcionando assim, as práticas humanas na busca do agir bem, do agir fiel à mensagem do Evangelho. Em outras palavras, é uma finalidade superior que depende da ação de cada um, em vista do que se busca, um ser humano integral, pleno, realizado e feliz. Para melhor fundamentar essa ideia, Ricoeur recorre ao clássico Aristóteles.

Sintetizando, da obra de Paul Ricoeur é possível entender que o enunciado negativo da proibição: "Não fazes a teu próximo o que tu detestarias que te fosse feito", deixa em aberto o leque das coisas não proibidas, e assim dá lugar para a invenção moral na ordem do permitido. Em compensação, o enunciado positivo como se lê no Evangelho de Lucas 6,31: "Como quereis que os outros vos façam, fazei também a eles", desperta claramente o sentido da benevolência que leva a fazer alguma coisa a serviço do outro. Ainda mais, o comando que se lê em Levítico 19,18 e em Mateus 22, 39: "amarás o teu próximo como a ti mesmo", marca "a filiação entre a solicitude e a norma e a enunciação de uma norma de reciprocidade" (RICOEUR, 1999, p. 256).

\section{A fonte aristotélica}

Paul Ricoeur resgata Aristóteles ao afirmar que o bem-viver só se dá com os outros. Inspirado nos textos aristotélicos da Ética a Nicômaco (1987), o filósofo francês argumenta que o sujeito se realiza no projeto originário da vida boa, mediante a procura da sua identidade pessoal, na busca fundamental e paulatina da constituição de si. Sendo assim, está claro que é por meio do autocontrole e da busca de uma racionalização das paixões, em que se educa para uma vida feliz, concluída, que se alcança o bem-viver. A esse respeito acompanhe o que diz Paul Ricoeur, quando fundamenta-se sobre Aristóteles:

O primeiro componente da perspectiva ética [vida-boa] é o que Aristóteles chama "viver bem", "vida boa": "vida verdadeira", [...]. A "vida boa” é o [...] próprio objeto da perspectiva ética. Qualquer que seja a 
imagem que cada um faz para si de uma vida realizada, esse coroamento é o fim último de sua ação (RICOEUR, 1999, p. 203).

$\mathrm{Na}$ herança aristotélica, a ética é caracterizada pela sua perspectiva teleológica, e define-se pelo predicado "bom" como uma finalidade da vida boa, adquirida através do agir bem. Vale ressaltar que a tradição aristotélica no pensamento ricoeuriano está inevitavelmente atrelada com a tradição kantiana, como é possível observar:

Propomo-nos estabelecer, [...] não sem uma grande atenção aos textos fundadores dessas duas tradições: 1) O primado da ética sobre a moral; 2) a necessidade, para a perspectiva ética, de passar pelo crivo da norma; 3) a legitimidade de um recurso da norma à perspectiva, quando a norma conduz a impasses práticos [...]. Não veríamos, pois, Kant substituir Aristóteles, a despeito de uma tradição respeitável. Estabelecer-se-ia antes entre as duas heranças uma relação ao mesmo tempo de subordinação e de complementariedade [...] (RICOEUR, 1999, p. 201).

Paul Ricoeur leva a entender que ética e moral se complementam, andam juntas, apesar de a ética ser superior. Por ter que se fazer presente no momento em que existem ou julga existir situações conflituosas impostas pela moral, necessariamente a ética é solicitada a se fazer presente uma vez que a moral não tem segurança suficiente ou não resolve sozinha. Entende-se também que a ética vem para dar à moral o seu devido crédito ou lhe assegurar seu exercício legítimo e de modo adequado ao lugar e ao momento. Não obstante a tudo isso, é de bom alvitre recordar que a ética deve necessariamente passar pelo crivo da norma, para se enriquecer com a pretensão de universalidade, na passagem pelo momento moral. Isso leva a dizer também que a teleologia aristotélica se configura como a origem da deontologia kantiana e que ambas estão atreladas entre si. De forma que, a ética se apoia no predicado bom, aplicado à ação para a designação de si. Vale ressaltar, ainda, que a articulação da perspectiva ética com o momento moral no plano do bem-viver corresponde à "estima de si" e ao "respeito de si", respectivamente.

A estima de si na teleologia do bem-viver caracteriza-se como o reconhecimento próprio do dever de praticar ações boas e afirmá-las sempre; bem como de identificar as erradas para repudiá-las. Para isso é 
necessária uma avaliação constante de si, das ações humanas imediatamente práticas, como diz o próprio Ricoeur: “É, com efeito, nas avaliações ou estimações imediatamente aplicadas à ação que se exprime o ponto de vista teleológico (RICOEUR, 1999, p. 202)”. Desse modo, o sujeito que, ao julgar boas as suas ações, pela estima de si mesmo, buscará sempre o bem-viver.

A estima de si é uma decisão alternativa do jogo entre a ideia de vida boa e as decisões mais marcantes do existir humano: como carreira amores e lazer. Paul Ricoeur assevera que: "No plano ético, a interpretação de si torna-se estima de si. Em troca, a estima de si segue o destino da interpretação (RICOEUR, 1999, p. 211)". Dessa forma, o "si" sai enriquecido com a auto interpretação. O respeito de si situa-se no nível da identidade pessoal, já desde o seu processo de constituição. No entanto, sua plena significação só será alcançada no final da terceira etapa da perspectiva ética, ou seja, no momento do respeito e da justiça para com os outros, no campo das instituições justas. Pondera o autor em questão que: "O respeito de si, que corresponde no plano moral à estima de si do plano ético, só alcançará sua plena significação no fim da terceira etapa, quando o respeito da norma tiver se expandido com respeito a outrem e ao 'si-mesmo com um outro'"(RICOEUR, 1999, p. 238). Desse modo, o respeito de si e a estima de si, porém, revestido da lei moral.

Com esse trabalho de reflexão pessoal, no respeito para consigo e para com os demais, o ser humano sempre quer reconhecer o "sujeito moral da imputação", isto é, aquele que age. Isso é feito através, por exemplo, das perguntas: quem fala? Quem atua? Quem é o agente ou paciente? Quem é o narrador? Quem é o responsável? Todas essas indagações são feitas com o objetivo de despertar a consciência de serem pessoas humanas que buscam o bem-viver, com um fim ético. Essa busca, avaliada pelo imperativo da norma confrontada na comunidade social global, leva a pessoa a escolher o que é melhor para si. Ou seja, ela tem obrigação de estar "sempre" ponderando sobre suas ações, num processo infinito de abertura e crescimento para enfrentar as novas possibilidades e situações que vão aparecendo na vida. Desse modo de proceder, a pessoa humana terá a esperança de se chegar mais madura na sua aspiração de pessoa 
adulta, capaz de "con-viver" consigo e com o outro. Desse modo, será capaz de ver a si como um outro e o outro como si mesmo.

A partir dessa perspectiva, o bem-viver ricoeuriano, que possibilita uma maturidade ética ao ser humano, com seu olhar de apreciação sobre si mesmo, auto-avaliando-se por meio da interpretação do texto de sua ação no plano ético, torna-se "estima de si". Entende-se que essa maturidade ética se desenvolve num processo dialogal, configurando-se aos padrões de excelência da vida boa que, por sua vez, acabam por desenvolver-se na hierarquização da práxis. Na prática, tudo acontece ao examinar as ações humanas, interpretando o seu atuar e confrontando-o com os padrões de excelência. O ser humano nesse estágio estará apto a tecer uma apreciação de si mesmo como autor de suas ações. Sobre isso Paul Ricoeur pondera que:

Esses padrões de excelência são regras de comparação aplicadas aos resultados diferentes, em função de ideais de perfeição comuns a uma certa coletividade de executantes, [...]. Vemos quão precioso é esse recurso aos padrões de excelência da prática para refutar ulteriormente toda interpretação solipsista da estima de si (RICOEUR, 1999, p. 207).

Paul Ricoeur enfatiza, assim, que os padrões de excelência têm um papel social fundamental ao instigar o sujeito a viver não somente fechado em si mesmo, mas educado para a vida coletiva. Esses padrões de excelência possibilitam ao sujeito compreender que ele vive inserido na vida em sociedade, na qual é julgado. Suas práticas são atividades cooperativas, cujas regras constitutivas são estabelecidas socialmente. Isso não quer dizer, entretanto, que esse caráter cooperativo não suscite controvérsias, porém, a intenção delas é levar o sujeito a refletir cada vez mais no sentido de se auto-conscientizar de que ele não é executante solitário de sua vida. Ricoeur, assevera que: "A primeira grande lição que guardaremos de Aristóteles é de ter procurado na práxis a ancoragem fundamental da perspectiva da "vida boa". A segunda é de haver tentado constituir a teleologia interna à práxis princípio estruturante da perspectiva da "vida boa"' (RICOEUR, 1999, p. 206). Para ele, o princípio da hierarquização da práxis dá-se de uma forma ascética, em escala espiralada, de superação, buscando um crescimento cada vez maior. É, portanto, um processo de 
depuração constante do ser, pois apesar de a boa práxis já ser uma ação boa, deve sempre crescer de forma que uma ação boa se inclua à outra como suporte sucessivo de amadurecimento constante.

A hierarquização da práxis, na perspectiva da ética ricoeuriana, mostra enfim, que a finalidade interna da ação humana é a deliberação que busca a adequação do que nos parece melhor para o viver prático. Isso exige que o ser humano conheça a singularidade, isto é, que chegue à prática da prudência ou sabedoria prática, por meio da qual saiba pesar as vantagens e inconveniências no planejamento da vida, rumo ao bem viver. Cumpre entender que, "na verdade, a prudência é uma virtude e uma parte da honestidade, como afirmam santos e filósofos" (MAGNO, 2017, p. 26).

Percebe-se nas palavras de Ricoeur a ideia de crescimento espiralado nas ações humanas que conduzem a um dilatar constante e progressivo, sob a ideia de uma vida concluída e ascética:

Lembremos de que maneira, sob a pressão da teoria narrativa, fomos conduzidos não somente a dilatar como também a hierarquizar o conceito da ação de maneira que fosse levado ao nível da práxis; desse modo, colocamos em alturas diferentes na escala da práxis, práticas e planos de vida, [...]. É a mesma hierarquia da práxis que iremos percorrer de novo, [...] do ponto de vista de sua integração ética sob a ideia da 'vida boa' (RICOEUR, 1999, p. 238).

Entende-se que essa ideia de hierarquização da práxis e padrões de excelência estão totalmente em consonância com o plano ético de vida boa na antropologia filosófica de Paul Ricoeur. Plano ético esse que se estende numa teleologia interna à ação e que, por sua vez, reflete propositadamente num grau mais elevado da integração das ações nos projetos da globalidade, incluindo, por exemplo, vida profissional, a vida de família, a vida de lazer, a vida associativa, bem como a vida política. Trata-se enfim de especificar genuinamente os vagos ideais do bem-viver humano, valendo-se da phronésis ou prudência aristotélica como paradigma de orientação prática. 


\section{A fonte kantiana}

Paul Ricoeur fundamenta a sua ética e moral herdadas de Aristóteles na deontologia kantiana, e elas se articulam conduzindo a vida de maneira que, com o auxílio uma da outra, a vida seja sempre boa. Entende-se que é nessa articulação, e no relacionar-se, que há uma ruptura entre a teleologia humana que conduz à ação e a deontologia que dita as regras universais de convivialidade, a fim de se construir uma boa convivência entre os traços éticos e morais da existência coletiva, conforme pondera o próprio Ricoeur:

Sem negar de forma nenhuma a ruptura operada pelo formalismo kantiano com relação à grande tradição teleológica e eudaimonista, não é inapropriado marcar, de um lado, os traços pelos quais essa última tradição manifesta-se na direção do formalismo e, por outro lado, aqueles pelos quais a concepção deontológica da moral permanece ligada à concepção teleológica da ética (RICOEUR, 1999, p. 238).

Segundo Paul Ricoeur, percebe-se que a ética aristotélica manifesta-se juntamente com o universalismo kantiano e que a obrigação moral não existe sem a perspectiva da vida boa. Argumenta-se que a ruptura e ancoragem do momento deontológico com o enfoque teleológico tornou manifesto pelo lugar que ocupa em Kant o conceito de boa vontade. Enquanto em Aristóteles, compreende-se na sua meta-ética que o "moralmente bom" significa "bom sem restrição" a fim de criar as condições necessárias e suficientes para determinar enfaticamente a questão do bem, pela razão prática, em Kant, o portador do predicado "bom" é a vontade. Entretanto, certa continuidade entre as duas perspectivas é preservada, conforme aponta Ricoeur:

Podemos homologar o conceito kantiano de vontade com o poder de colocar um começo no curso das coisas, de se determinar por razões, poder que, dizemos, é o objeto da estima de si. Mas a vontade, toma, na moral kantiana, o lugar que o desejo razoável ocupava na ética aristotélica (RICOEUR, 1999, p. 240). 
Em outros termos, entende-se que a vontade é a faculdade de agir em plena consonância com a representação nômica na busca do bem viver, "já que viver bem (isto é, viver eticamente), é cumular a vida de múltiplas significações” (ANDRADE, 2000, p. 97).

A vontade toma na moral kantiana, o lugar que o desejo razoável ocupa na ética aristotélica. Esta, na sua relação com a lei, é o que inspira o ser humano na pergunta kantiana: o que devo fazer? É uma pergunta que se exprime de uma maneira dependente do imperativo, enquanto o desejo se afigura como optativo. Enfim, a vontade não é senão uma razão prática. É intenção de todo procedimento crítico levar a condição finita da vontade à razão prática, concebida como autolegislação, como autonomia. Somente nesse estágio ou fase é que a pessoa, pelo respeito de si, é capaz de submeter-se à limitação e, ao reconhecê-la, alcança uma boa base no estatuto moral. Para tal estatuto, entende-se que a mediação a ser buscada, a exemplo do processo de educação para o sujeito coletivo, procura na norma o seu fundamento ou embasamento consensual:

A educação vai em busca, em certo sentido, da passagem pela norma. Essa passagem lhe é necessária para não se deixar levar apenas por inclinações momentâneas, [...], diante dos conflitos das objetivações e formalizações da norma, os questionamentos e as dúvidas levam-nas a reencontrar novas dimensões da perspectiva ética (GARRIDO, 1994, p. 173).

Entende-se assim a necessidade de um processo reflexivo, cujo processo de maturidade pode ser adquirido no caminho da educação possível para o sujeito coletivo. Entende-se que esse processo é urgente na atual conjuntura sociocultural - em que se encontra a mentalidade educativa - e que se percebe fraturada e em pleno descaminho ético. É o fomento de um ser que seja ético, educado, que busque crescer pela reflexão socializada, universalizada. Nesse sentido, entende-se que:

[...] é a prova de universalização que dá à máxima sua significação específica, ao mesmo tempo que essa prova define pela primeira vez o formalismo, como testemunha, a esse respeito, a formulação mais geral do imperativo categórico: 'Age unicamente segundo a máxima que faz com que tu possas querer ao mesmo tempo que ela se torne uma lei universal' (RICOEUR, 1999, p. 243). 
As máximas das ações sempre são universalizadas. Estas, procuram universalizar as ações, justamente porque a faculdade de desejar tem a tendência de buscar sempre o amor de si e a felicidade pessoal, daí a necessidade de uma lei para regrar as ações, até que o homem adquira autonomia no seu agir. Logo, a autonomia é, por assim dizer, o "metacritério", a autolegislação que leva o ser humano educado coletivamente ao exercício da liberdade.

Em suma, estas ponderações levam o ser humano a perceber que será mais livre, na medida em que for capaz de dominar suas vontades; domínio possibilitado pela maturidade de uma formação integral. Quando a autonomia substitui a obediência ao outro pela obediência a si-mesmo, perde todo o caráter de dependência e submissão. Com isso, busca-se a identidade de uma pessoa que, como adulta, possa ter reconhecimento e compreensão de si e que seja capaz de responder: EIS-ME. Desse ponto de vista, a esta reflexão, em busca da identidade narrativa do si, é proposta entre a identidade como IDEM e a identidade como IPSE. É uma proposta interessante que marca o momento ético do sujeito que responde por si e identifica as ações de outros (RICOEUR, 1999, p.137-198).

Uma das coisas mais profundas na antropologia filosófica de Paul Ricoeur em relação ao si, é a sua visão nova de que o si não é o eu como se entendiam nas filosofias do sujeito, como por exemplo o eu exaltado por Descartes e o eu destituído por Nietzsche. Nessas filosofias "o eu é empírico e independente, sem confrontação com o outro, negligenciando por isso a intersubjetividade" (GARRIDO, 1994, p. 117). Ricoeur opõe o si ao eu. O si é o termo reflexivo de todas as pessoas gramaticais. Ele denomina todos os pronomes pessoais: eu, você, nós, etc. Desse pensamento, Ricoeur quer nos transmitir que o amadurecimento do sujeito que busca uma vida boa realiza-se no contato com o outro, na intersubjetividade genuína, onde dá lugar não só ao racional como também aos sentimentos que compõe o ser humano em toda sua integralidade.

Sendo assim, "é o sujeito que mediante reflexões, pelas mediações e em confrontação e assunção do próprio de si, quem volve a si mesmo como um si maduro, que foi reconhecido reflexivamente" (GARRIDO, 1994, p. 118). Enfim, este sujeito do si é, portanto, aquele sujeito que se proporciona uma ampliação e maturação constante da personalidade. 
Nisso, dá-se o momento crítico das ilusões, em que a consciência é vista como tarefa, não como ponto de partida, mas de chegada. "A consciência deve ser capaz do outro, do inconsciente" (CÉSAR, 1998, p. 40). Dito de outra forma, a intenção é que o eu imediato, egoísta se apague para que nasça o si reflexivo.

\section{Identidade e Ipseidade}

Ressalta-se que no nível ontológico, na sua hermenêutica do si, Ricoeur mostra que a identidade só pode ser automaticamente pessoal quando envolve a responsabilidade para assumir os conflitos que se apresentam e a busca de sua superação. Esses conflitos, muitas vezes, são gerados pela equivocidade da identidade presente na dialética da mesmidade e da ipseidade. Num primeiro momento, é possível observar em Paul Ricoeur o esclarecimento do termo identidade. Ele enfatiza as diferentes significações deste termo da seguinte forma:

A identidade no sentido do idem emprega ela própria uma hierarquia de significações que nos explicitará o momento desenvolvido, [...] do qual a permanência no tempo constitui o grau mais elevado, ao que se opõe o diferente no sentido de mutável, variável. Nossa tese constante será que a identidade no sentido do ipse não implica nenhuma asserção concernente a um pretenso núcleo não-mutante da personalidade (RICOEUR, 1999, p. 12).

Essa exposição ricoeuriana é interessante, pois mostra a distinção interna da genuína identidade de um ser humano que, quando toma o caminho do amadurecimento contínuo, se reconhece um ser aberto ao crescimento constante. Trata-se, pois, de um ser inacabado e em constante aperfeiçoamento. Por um lado, a identidade como idem, conforme sugere o próprio radical da palavra, é daquele sujeito "único em seu gênero", que tem como grau maior, o ser idêntico a si e imutável através do tempo, diríamos imaturo. Por outro lado, a identidade como ipse, representa o sujeito que assume o diverso de si, como constitutivo de si. Um si que passa pela experiência da alteridade, que leva em conta a própria dialética do 
si-mesmo e do outro. É um sujeito que é agente de suas ações e paciente, no prazer ou na dor do seu semelhante.

Enfim, é uma identidade

primeira sendo adequada aos 'traços objetivos ou objetivados do sujeito falante e agente', enquanto a outra caracteriza o 'sujeito capaz de se designar como sendo si mesmo o autor de suas palavras e de seus atos, um sujeito não-substancial e não-imutável, mas contudo responsável por seu dizer e fazer"' (CÉSAR, 1998, p. 61).

Essa polaridade da identidade pessoal é interessante em Ricoeur, uma vez que ele mostra que o idem só se remete à conotação "mesmo". Ele para no nível impessoal, o qual deixa de lado o aspecto ético, item fundamental da filosofia ricoeuriana na constituição do si. Já no nível do ipse, muito valorizado por Paul Ricoeur, associa-se o "pessoalmente", isto é, alcança o nível pessoal, fundamental nas inter-relações concretas do bem-viver, em que o sujeito é fiel à sua promessa apesar das transformações. E, é nessa fidelidade transformadora que, simbolicamente, o sujeito morre para as ilusões e para a consciência ingênua a fim de chegar à consciência crítica. $\mathrm{O}$ desdobramento da ipseidade em seus graus mais elevados: estima de si e respeito de si, tem mostrado a importância da dimensão ética do si, no plano ético ricoeuriano do bem-viver, em sua estrutura triádica: a estima de si, a solicitude para com os outros e a justiça em relação a cada um.

Em suma, este processo que se desenvolve nas suas deliberações e na avaliação de suas ações é realizado num campo estritamente ético, campo este em que o homem, no exercício da alteridade, alcança a virtude do homem sábio e prudente. Caracteriza, enfim, o homem que aprende a criar e desenvolver condutas práticas apropriadas para cada situação singular, sem, no entanto, deixar de ser cuidadoso com os outros e íntegro com aquele que não conhece. Sendo assim, o sujeito no desenvolvimento de suas potencialidades vai se desenvolve como pessoa e, como diz Paul Ricoeur, (alhures) "vai exercitando a sabedoria prática no seu atuar em meio aos desafios conflituoso da vida, desenvolvendo de forma espiral, a perspectiva ética a que é chamado realizar". 


\section{Considerações finais}

A questão da ética do bem-viver, segundo Paul Ricoeur, em plena intersecção com a perspectiva evangélica, consiste em uma dialética crítico-reflexiva sempre presente na vida cotidiana em que uma só vertente não basta, faz-se necessário, pois, levar em conta o outro e as suas circunstâncias. "É notável que o princípio da ação recíproca também seja chamado de princípio da comunidade ou até mesmo princípio do comércio (RICOEUR, 2006, p. 167). Consequentemente, quando se adquire uma consciência da necessidade de educação para o coletivo, o ser humano educado nesta perspectiva comunitária para a vida coletiva tem consciência que deve sempre avançar a reflexão sobre o aspecto ético da estima de si, no seu desdobramento como solicitude para com os outros, em face da busca dinâmica do bem-viver. Sabe-se consciente de que não se pode ser feliz quando o seu semelhante está em situação de miséria.

Portanto, a partir da teologia cristã, este ser humano educado para uma formação integral e coletiva contribui para a efetivação do bem viver. Ele sabe, então, que a efetivação da vida boa só será possível na seara social e comunitária, em detrimento de uma vida isolada. Se o bem-viver não é um estilo de vida fechado em si mesmo, mas voltado para a alteridade, então, na perspectiva do Evangelho e da antropologia filosófica de Paul Ricoeur, é preciso reconhecer que faz-se necessário um novo caminhar para além da estima de si puramente. E este caminhar dirige-se diretamente para o viver com e para os outros nas instituições justas.

Então, a vida boa na perspectiva da ética ricoeuriana é uma vida marcada pelo desejo constante de con-viver, de crescer sempre e de forma espiralada, e que tem na meditação, no processo de conversão e de ascese cristã, um ideal a ser buscado. Deste ponto de visa é possível afirmar a relevância do pensamento explicitado na obra de Paul Ricoeur, que contribui significativamente para que o ser humano nunca perca de vista a consciência de sua tarefa no Cosmo. Ou seja, este tipo de literatura remete aos desafios de uma busca constante pela realização humana de modo coletivo, comunitário, em que a solidariedade, o respeito e o valor pela criatura humana ocupam um lugar central. Neste sentido, é possível entender que a hipótese de que a vida boa se dá de modo coletivo em detrimento de 
qualquer tipo de preconceito e ou de injustiça pois que “[...] Deus não faz diferença entre as pessoas" (cf. At 10,34).

Sendo assim, a reflexão teológica e ética fundamentada na obra de Paul Ricoeur tem uma relevância ímpar na atual conjuntura, eivada pela mentalidade egocêntrica de uma cultura global voltada para os seus problemas domésticos, quando na verdade esta humanidade encontra-se frente ao grande desafio de colaborar de modo coletivo, por exemplo, frente à necessidade de cuidado com o meio ambiente que reivindica o cuidado coletivo a fim de conter o grave quadro de degradação ambiental e de crise humanitária. É possível entender que a obra de Paul Ricoeur aponta e aconselha o leitor para o entendimento de que se uma pessoa está adoecida, a humanidade não pode afirmar que está com saúde e, se há um desastre ambiental em qualquer lugar do planeta, os demais habitantes das localidades distantes quando possuídos de consciência coletiva não devem se sentir indiferentes, mas envolvidos diretamente na preocupação e solidariedade para com todos.

\section{Referências}

A BÍBLIA DE JERUSALÉM. Nova edição revista. São Paulo: Paulinas, 1985.

ANDRADE, A. C. Ricoeur e formação do sujeito. Porto Alegre: Edipucrs, 2000.

ARISTÓTELES. Ética a Nicômaco. Trad. Leonel Vallandro e Gerd Bornheim. São Paulo: Nova Cultural, 1987. (Os Pensadores). 288p.

CÉSAR, C. M. (Org). Paul Ricoeur - ensaios. São Paulo: Paulus, 1998.

GARRIDO, S. V. A Questão da Educação e da Identidade Segundo Paul Ricoeur, 1994 [225f]. Tese (Doutorado em Educação) — Faculdade de Educação, Universidade Estadual de Campinas, Campinas/SP, 1994.

KOJÈVE, A. Introdução à leitura de Hegel. Trad. Estela dos Santos Abreu. Rio de Janeiro: Contraponto: EDUERJ, 2002.

MAGNO, A. Tratado sobre a prudência. Trad. Matteo Raschietti. São Paulo: Paulus Editora, 2017. 
RICOEUR, P. O Si-Mesmo Como Um Outro. Trad. Lucy Moreira César. Campinas, São Paulo: Papirus, 1999.

RICOEUR, P. Percurso do reconhecimento. Trad. Nicolás Nymi Capanário. São Paulo: Loyola, 2006.

TORRES QUEIRUGA, A. Repensar a revelação: a revelação divina na realização humana. Trad. Afonso Maria Ligorio Soares. São Paulo: Paulinas, 2010.

Recebido: 25/12/2017

Received: 12/25/2017

Aprovado: 08/04/2019 Approved: 04/08/2019 